\title{
Cultural Heritage as a Means for Local Development in Mediterranean Historic Cities-The Need for an Urban Policy
}

\author{
Yiota Theodora \\ Department of Urban and Regional Planning, School of Architecture, National Technical University of \\ Athens (N.T.U.A.), Patission 42, 10682 Athens, Greece; ptheodora@arch.ntua.gr
}

Received: 8 February 2020; Accepted: 20 March 2020; Published: 26 March 2020

\begin{abstract}
Urban and regional development have not stopped engaging, troubling, and dividing the international scientific community and national and regional policy-making bodies. The wide range of consequences brought on by the current multifaceted downturn at all geographical scales requires the continuous investigation of practices and the designation of innovative mechanisms or tools to formulate new developmental axes for action, able to respond to contemporary needs and challenges. This holds true particularly in an age, such as the one we are currently experiencing, of network organization of infrastructures and functions dominated by the knowledge economy. Within this framework, we estimate that the response to an attempt to restructure production in Greece and increase support for its cities and regions could be sought by setting up collaboration networks with cultural heritageand support creative entrepreneurship as key developmental "elements", focusing on strategies for recovery, modernization, and a return to historic cities and regional settlements. Specifically, using inputs from a collaboration project among historic cities in the Mediterranean, and an ongoing research in fragmented insular regions with many historic cities and settlements in the Aegean, we maintain that the goal of restoring local communities could be sought though initiatives or actions to preserve and diffuselocal traditions and know-how in the framework of an overall urban developmental policy capable of ensuring ongoing collaboration and networking at all geographical levels and categories of space. In this rationale, this article attempts to contribute to the debate by stating proposals in the framework of principles and guidelines that should govern the formulation of this urban policy, which is still missing in Greece.
\end{abstract}

Keywords: local regional development; spatial planning and urban regeneration; spatial policies; cultural heritage; creativity and smart cities/communities; historic cities; collaborative networks

\section{Defining the Research Framework and Its Methodology}

The sweeping changes and socio-economic shifts, especially during the past 30 years, have signalled major developments in the structure and organization of the urban space at all relevant development perceptions and planning practices. The new circumstances and emerging trends compel us to define criteria to formulate the basic lines of action able to respond to contemporary challenges in urban and regional development. Undoubtedly, we are headed for the beginning of a new era regarding the role that spatial planning plays in developmental policy. In this direction, there is great concern regarding the definition of new models and how interventions are oriented so that cities and their broader areas can act as virtual development cores while preserving the identity of their historiccentres. This concern (in most cases) is expressed in an atmosphere of dispute or even tension, mainly due to the various perceptions regarding urban development and often conflicting interests [1-3]. 
Values like social justice and equality, protection of natural and cultural wealth, tradition, and creativity become more and more important in times of crisis, where new realities (i.e., globalized economic environment, tertiarisation of production, multiculturalism, etc.) do not appear to be mobilizing the same urban reshaping processes, nor do they have the same impact everywhere $[4,5]$. Unfortunately, in conditions like these (despite the growing interest and concerns for the shape, structure, and characteristics of the urban space and recognition of its development potential) the European Union's urban policy is still at an early stage, contrary to long-standing regional policy tradition [6-8].

In this context and considering the general concerns on issues of urban development at the European level, this article seeks to contribute to the scientific dialogue at a very critical point in time by underlining the need to change the way cities are developed and organised is viewed. More specifically, it stresses the importance of addressing the urban space downgrading at all levels of action (such as local, regional, national, European, international, etc.) through a broader multi-variable framework of an overall urban developmental policy supporting human resources, combating social exclusion, securing a quality urban environment, and strengthening the competitiveness of cities and regions, building on equality, justice, protection, and sustainability [9]. Emphasis is placed on the critical importance of supporting the production process, as well as on the importance of gaining the creativity and maintaining it at historic cities and settlements, as a means of socio-economic, cultural, and spatial development of the urban space and strengthening of their radiance. A "key" role is taken on by intangible cultural heritage and traditional professions that could function as catalysts for urban regeneration [10]. In particular, the arts professions and the new artists (considering in amongst the initiatives for the conservation or diffusion of local identity and know-how) could work as drives to modernize and restart local communities [10-13].

Along this line, what sparked the interest on the subject was the experience from a collaboration project among seven historic cities in the Mediterranean (each with a different culture and sectoral specialization, politico-social conditions, and urban environment quality) which brought about the need for networking and cooperation [12]. From this rationale, ongoing research in the Aegean aims at enriching the existing experience. Specifically, focusing on fragmented insular regions, it seeks to contribute to the discussion by supporting that the development of small, isolated or frontier islands can be achieved by managing their local human resources as well as natural and cultural heritage rationally organized in "networks of culture" of supralocal and supranational reach [13].

Both studies (a) bring about the importance of preserving or disseminating cultural heritage (tangible/ intangible), local traditions, and know-how as a means of urban-regional development [10]; (b) mark out how education and professional training contribute to the support and promotion of innovative sectors/local skills, and highlight the significance of preserving educational structures (universities, training schools) in central parts of cities and settlements in order to establish relations between sectors of creative entrepreneurship and local communities [14]; (c) verify that management and regulation of space should be governed by three basic principles, namely, (i) the principle of a single perspective on space, (ii) the principle of jointly evaluating the local individual characteristics, and (iii) the principle of inextricable correlation of developmental policy and spatial planning [13]; and (d) point out that the goal of restoring local communities could be sought though initiatives or actions to preserve and diffuse local identity, traditions and know-how, but within an overall, more flexible, urban developmental policy, able to ensure ongoing collaboration and networking at all geographical levels and categories of space (e.g., coastal, insular, mountain, boarder or frontier areas, etc.) [10,13]. These conclusions are confirmed in practice, as we study their impact on the developmental process, which gains particular interest in areas that undergo intense, often differentiated pressures, as is the case of historic cities and settlements which is the current subject of study (Sections 5-7). 


\subsection{Determining the Methodological Approach}

As mentioned above, this paper seeks to highlight innovative planning proposals for the development of cities and settlements of historical and cultural interest, which are experiencing degradation or abandonment. This interest is focused on approaches that aim to abate inequalities and re-start local communities on the basis of a concept that goes beyond fragmented physical planning interventions to underscore the importance of considering socio-economic parameters that are primarily associated with the production structure, accessibility/networking of areas, as well as technical and social infrastructure. The key to local development lies in the management of the natural-cultural heritage and local human resources through the encouragement and establishment of spatial, sectoral and social networks of cooperation and communication.

Research focuses its interest on vulnerable areas of central urban and/or rural regions, where the coexistence of comparative advantages in and pressures on the natural or manmade environment raises a number of issues to be addressed. Where the unconsidered adoption of development models (incompatible with the local identity, carrying capacity and local needs) alter the quality of localities and lead to the disappearance of traditional production models. Such areas are further deteriorated by the prevalence of disorderly urban or tourist development, the increasingly intensified investment interest in infrastructure of supralocal reach, and implementation of fragmentary interventions with diverse impact on the natural or built environment. The perpetuation of the above phenomena has fuelled the (re)production of identical residential patterns while destroying landscapes and seascapes as well as natural or cultural assets of unique interest.

In these circumstances, the problem lies in the absence of a comprehensive clearly formulated urban policy capable of ensuring development by capitalizing on the local comparative advantages. It is therefore not an issue of having spatial development proposals in place, but rather incorporating them into an urban policy with clear principles and priorities at local level on the basis of broader spatial networking and partnerships. It is in this direction that this paper wishes to contribute. Hence, the utilization of the research experience from the Mediterranean and Aegean areas relies on a methodology of synthetic monitoring and assessment of the results and open issues highlighted by the specific proposals. Each proposal contributes in its own way to the design of the desired urban development policy $[12,13]$. In particular, key determinants of the relevant discussion have been (a) the goals/objectives of the specific proposals in conjunction with the methodology and approaches adopted, (b) the development instruments proposed, (c) the spatial scale of reference and the space category on which the research interest is focused, (d) the contracting entity and participants, and (e) the existence of financing. The degree of maturity of their respective findings has played an equally significant part, given that research in the Mediterranean has been completed, while in the Aegean, it is still in progress. Currently, it would not be possible, nor would it make sense, to embark on a comparative overview of the proposals. It would be interesting, however, at a later stage (after the completion of the research in the Aegean) so as to demonstrate whether, and under what conditions, the creation of "cultural networks" in the Greek insular areas could serve as a means of developing remote islands or island complexes. It is a proposal that could be utilized in the framework of the national development strategy on Greek insular regions with a view to limiting or even preventing tourism monoculture.

On this basis, the principles and guidelines that should govern a new, contemporary development policy (at national or supranational/transnational level) are determined by concurrently performing two searches which feed back into each other (Figure 1). The first defines the broader context of the discussion, while the second enriches the discussion by utilizing the research experience, hence it is more practical. Therefore, the first search primarily delves into (a) the contemporary developmental role of cities in a globalised environment of networked space, (b) crucial local or regional development issues, and (c) the urban regeneration of historic cities and settlements through the management of cultural heritage (Sections 2-4). The interest of the second search is focused on presenting the two proposals in order to distinguish their individual contributions to the identification of the key issues 
to be addressed by an urban policy. Initially, their subject, targets, participants, and methodology adopted are set forth (Sections 1.2 and 5), and the findings/conclusions are listed in thematic areas (Section 6). Subsequently, the critical issues that have arisen from these two searches, and remain unresolved, are laid out (Section 7). The article is concluded by an overview of suggested principles and guidelines for the planning of a new overall urban policy in terms of protection, sustainability, and social justice (Section 8).

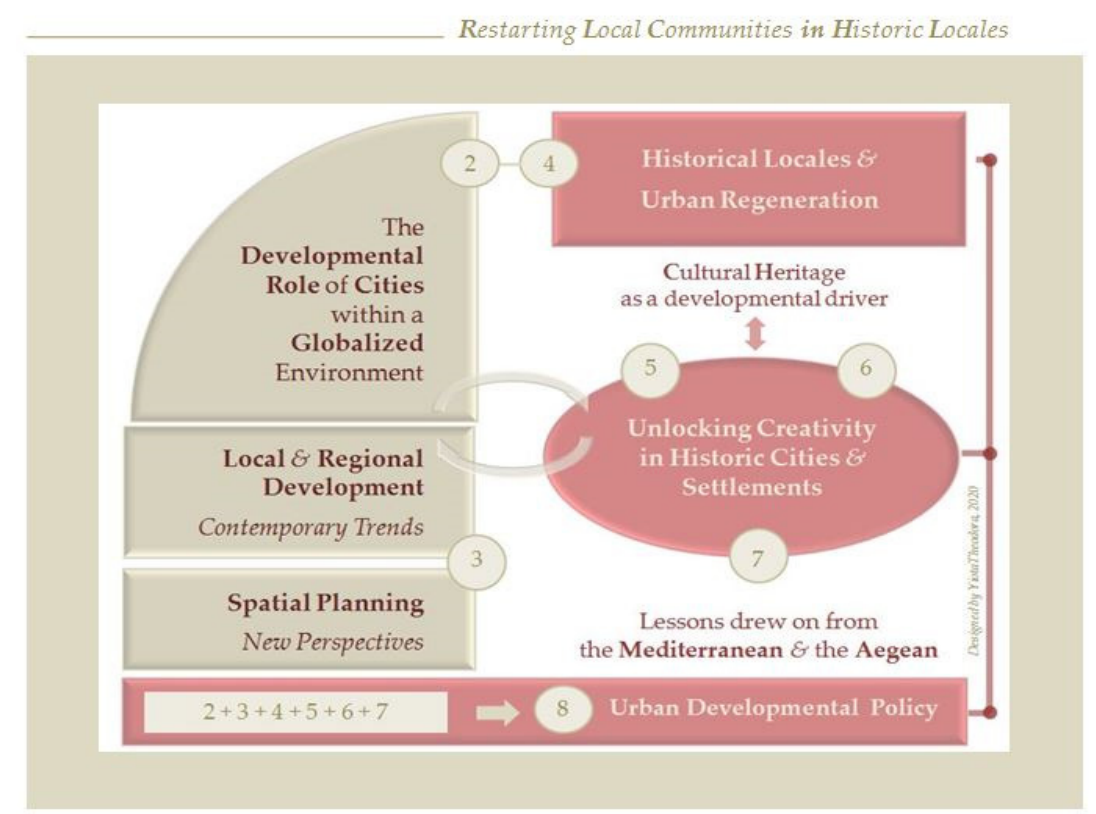

Figure 1. Themethodological approach and its basic levels of investigation (designed by Yiota Theodora, 2020).

\subsection{The Mediterranean and Aegean Areas as Places of Referenceand Investigation}

Both the Mediterranean and Aegean areas are particular loci where one encounters a significant number of historic cities but also a host of historic settlements spread out in rural regions, mainly in coastal, insular and mountain areas in the continental and island segments of countries. Indubitably, remarkably diverse areas connected by many common challenges. Meeting these challenges requires cooperation that reaches across borders. This was the main impetus for the selected researches.

The first case of reference is the MEDNETA project which was implemented during the period 2013-2015 under the Cross-Border Cooperation (CBC) Mediterranean Sea Basin Program (CBC is part of the European Neighbourhood Policy (ENP) and its financing instrument is the European Neighbourhood and Partnership Instrument (ENPI) (wwww.enpicbcmed.eu)). The Program aimed to reinforce cooperation between the European Union and partner countries' regions placed along the shores of the Mediterranean. This project is a Euro-Mediterranean initiative to develop historic cities, which focuses on the importance of supporting intangible cultural heritage and tradition to restart local communities, promotes them as a dynamic "gateway" for urban and regional development and supports the real catalytic role that a return of creativity would have on their historic city centres (MEDNETA Partnership: Greece: NTUA (Beneficiary)/Greek-Italian Chamber - GIC, Italy: Social and Economic research Centre for the South of Italy _ CRESM/Superior Institute of Artistic Industries _ ISIA, Spain: Valencian Institute for Conservation and restoration of Heritage - IVC+r, Tunis: Association for the Safeguarding of the Medina of Tunis - ASM, Lebanon, Beirut: GAIA-heritage Institute of Urban Planning _ GAIAh, Palestine, Hebron: Birzeit University - Department of Architectural Engineering _ BZU). The key would be networking traditional arts professions and know-how. The project was evaluated positively at the European Union level and gained distinction among a significant number of initiatives for urban regeneration [10-12]. The project's results were successfully communicated amongst participating countries and beyond. The author participated in this creative 
Euro-Mediterranean scientific team as a senior researcher and a communication manager from the NTUA's School of Architecture.

The second case is an ongoing non-funded research project under the scientific coordination of the author. It investigates the specificities of the Aegean Sea in an attempt to seek ways to sustainably develop its vulnerable areas-namely, islands and insular areas that are under intense pressure of degradation but which also have comparative advantages that could be leveraged as development drivers. A solution is sought from setting up knowledge and culture networks of supralocal reach. The proposed key means are the local human resources and natural-cultural heritage [13]. The Aegean was selected mainly due its geostrategic and geo-economic significance. It is a particular locus where different qualities and contrasts coexist. An area which hosts places of history, memory and culture, and geo-sites which represent significant moments in the Earth's history, natural ecosystems, and elements of tradition and architectural heritage. The above have formed landscapes and seascapes of unparalleled beauty and sensitivity that have to be evaluated at local and interregional level. With the existence of a multitude of islands, the border areas of the Aegean are of particular interest, with the small frontier islands constituting a vulnerable category of space which, due to scale, intensity of spatial issues, and developmental prospects, can work as a challenging place of investigation and practice. Therefore, they were selected as a pilot research area (Sections 5.2, 6.2 and 7.2) (Figure 2).

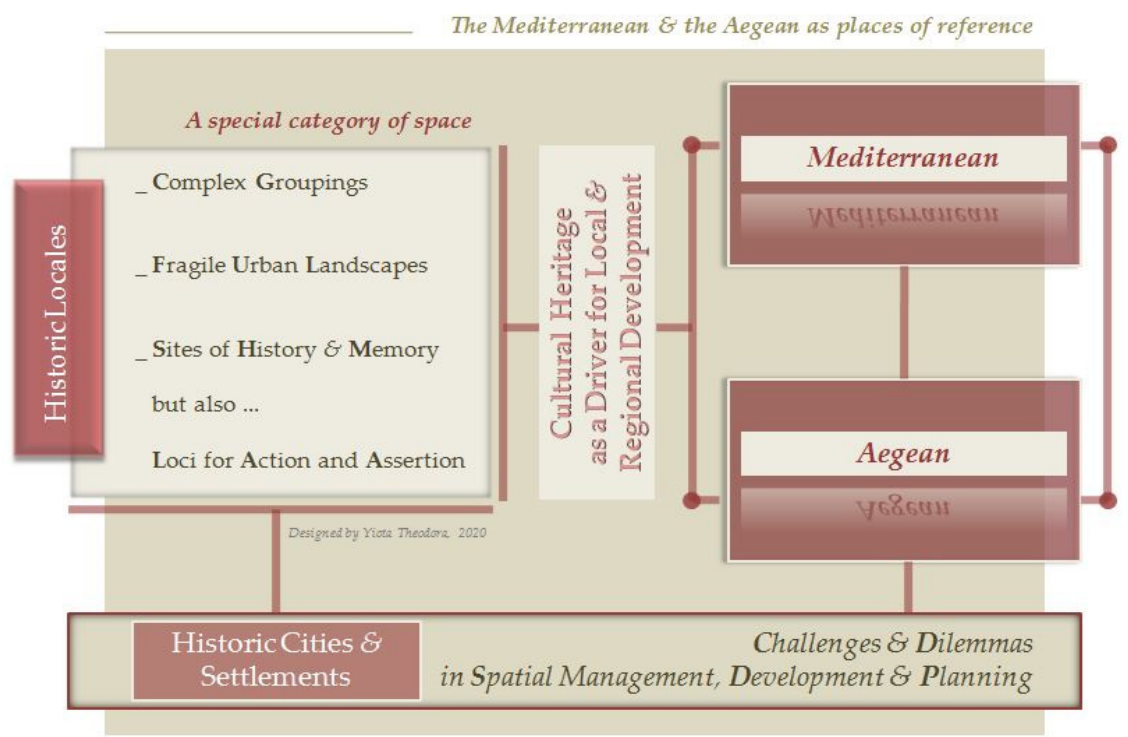

Figure 2. Challenges \& Dilemmas in Planning Historic Locales: The Mediterranean and the Aegean as places of reference (designed by Yiota Theodora, 2020).

The two choices were not random. Acknowledging that development is not a spatially neutral process, focus on the particular features of locations and the comparative advantages concentrated at a level of the sectoral structure of production. Both seek to restart local societies by encouraging actions that would establish spatial and sectoral "networks of collaboration" that would be national and trans- national in scope along the lines of environmental sustainability, spatial development and economic growth, and support of local human and cultural resources. They are urban development propositions of great importance, since their entire philosophy and direction attempt to respond to contemporary trends and prospects by making use of new challenges (human resources, natural and cultural heritage, creativity, historic cities and settlements). Challenges that could be theoretically founded on a very widespread recently developed theory making the assumption that the city is the place where creativity and innovation grow, not so much as a result of technological developments, but because of the presence of history and tradition and a class of professionals that constitute the root cause of innovation, new forms of economic activity, and wealth [3,15-19]. The proposals for urban regeneration which are put forward by the selected researches are presented in Sections 5-7, below. 


\section{The Developmental Role of Cities within a Globalized Environment in Times of Crisis}

Cities, irrespective of whether they develop gradually through time or are the result of specific planning, constitute the material expression of the variety of societies formed for historical reasons and hence constitute historical events [20]. They are dynamic systems of a socio-economic-cultural nature, since the majority of population and "key" sectors of all functions, infrastructure and recreation/leisure activities accumulate in cities and their greater areas. Therefore, their spatial functional range in the international allocation of urban activities and in the geopolitical sphere of influence of states becomes of particular importance for the development of social systems and the prospects of strengthening national economies [21]. However, apart from being driving forces, cities are also faced with a multitude of socio-economic and environmental problems, quite critical for their development, due to the multiple effects they have on the quality and dynamics of their urban environment and the weight of their international image.

Without ever ceasing to constitute a consistently equally topical interesting issue, within the new conditions of the information society and immaterial economy (in other words the knowledge economy), cities—as historical events and main recipients of human activities/functions—are called upon to play a new and even more important developmental role in the national scale of countries and beyond [22-24]. Indeed, during the current decade-and because of the socio-economic crisis—cities will become once more the focus of discussion. This time, cities are being redefined in the framework of the general spatial functional reclassifications that are under way. Within a network-organised globalized economic environment, cities are, now conscientiously, addressed not as autonomous development cores but as "hubs" of broader urban correlations integrated within powerful global networks, independent of administrative boundaries and/or national borders [21,25]. Values like tradition, natural-cultural heritage, history, memory, and creativity are being showcased as planning principles, necessary to protect the heterogeneity of the socio-economic and cultural sectors $[3,20]$. This can be confirmed in modern literature, in European Union (EU) official documents and in the orientation of EU policies on developing European cities and regions $[4,6-8,11,15]$.

At the same time, within an international environment that tends to become homogeneous in terms of form, structure and function, there is an additional concern in relation to the future prospects of cities since, based on experience, it appears they suffer the consequences of the crisis more intensely than regional areas $[4,5]$. This position, under no circumstances, limits the lines of inquiry, which also concern the future of urban networks (particularly those that are historical) encountered in rural regions, and especially those of the insular and mountain areas-in other words, areas in which we still encounter significant elements of cultural heritage while, in several instances, the consequences, whether the monoculture of tourism or abandonment shall shape other conditions and dynamics and bring up a series of crucial issues concerning spatial development, protection, and regulation. Thus, prevention and addressing intra-urban inequalities and ensuring the conditions for networking cities and settlements at national and supra-national levels become issues of great political significance [13,21].

In this framework of multiplex processes (resulting from the new conditions prevailing in the international markets and the choice of the dominant development model within states at national scale) - where spatial transformations make up a complex situation of urban dynamics-new spatial forms of development are emerging, while the modus operandi of central urban areas is changing due to the different role they acquire $[9,21]$. Countries have long ceased to be envisaged as closed, autonomous systems, while cities seek collaboration by setting up production and distribution networks going beyond the national scale of states. The urban space acquires new forms and takes up new dimensions, where new hierarchies prevail through the organisation of spatial, thematic, quality networks in all territorial scales [13]. In such conditions of spatial reformation and of urban alliances, there is evidence to be found that it is not only cities with the infrastructure to generate knowledge, innovation, and know-how that contribute to the developmental process but also cities that can appropriate such a process in order to improve production conditions and put their tradition and creativity to use. At 
the same time, countryside settlements gain a new dynamic, a portion of a multifunctional space, which should not be treated the same as agriculture. Rural regions constitute complex settlement sites with significant diversity. They are, in other words, complex economic, physical, and cultural sites that cannot and should not be dealt with on the basis of population size, agriculture, and natural resources. They are areas which differ significantly amongst themselves, but also within themselves, so it is therefore necessary to also estimate their individual qualities in each instance in order to make use of the capacities to the greatest extent possible-a fact that in the instance of nations like Greece (with a significant number of rural areas where settlements and urban networks with a unique history and appearance) demands we re-examine the relationship between the city and countryside and redefine the role of cultural heritage, human resources and their skills in the developmental process. Already, the stance toward tackling issues which concern protecting historicity, conservation, development of historic citiesand settlements, and their seamless adaptation to modern life is being steadily reinforced. There is a similar interest for utilizing the historic centres of cities as dynamic "pockets of memory and action". These trends are extremely critical in spatial management and planning because they bring up issues of how to deal with these but also due to the major transitions that can be brought about in the strategic choices of urban policies $[10,13]$.

\section{Contemporary Trends in Local and Regional Development and New Perspectives for Spatial Planning}

Differentiation of the economic activity model in the framework of the immaterial economy has, without a doubt, affected the urban development model, strengthening some cities more than others [24]. The model of the post-industrial or post-modern metropolis is now changing. It is evolving, taking up forms that rely upon new principles, organizations, financial management, coordination, and management models. Meanwhile, cities (mostly of average or low population count) tend to record a declining developmental performance, despite the wealth of their natural and manmade resources (especially those located in mountainous and island regions). Some of them, in an effort to enhance their attractiveness, attempt to boost their competitiveness by focusing on specific areas of activity and infrastructure (tourism, recreation, energy), often at the risk of deteriorating the local character of their historic sections $[10,13]$.

Key means of production, services, and technical and social infrastructure are all network organised, and the intensification of international competition and the changes it brings to the spatial allocation of investments are forcing governments to develop strategies specifying the role of cities and their greater areas in order to support their local communities at national level and to strengthen their position on the international map. The question, therefore, is how will cities manage to deal with their problems, improve their image, and strengthen their position on the international map by preserving and maximising on the authenticity of their local identity and tradition, and indeed in an economic recession? This is a question that may not have any easy universally acceptable answers and definite solutions. But, all the same, a question that addresses critical issues and thus underlines the need to review the urban development and showcases the importance of creating an overall and expressly formulated urban policy.

There have, at times, been several attempts to ascribe the new character and image of modern cities, a debate that started sometime in the ' 80 s and ' 90 s. Since then, in an effort to identify a range of developmental characteristics that the urban fabric, in its contemporary form, must have so that cities can be in a position to successfully address the new needs and challenges, various descriptions have been voiced, such as sustainable city, entrepreneurial city, informational city, innovative city, smart city, network city, and more recently the model of the creative city which seems to prevail $[16,17,22,25-28]$. It describes a new method of strategic planning which examines the way in which people think, plan, and live creatively in the city - a city which, without necessarily being superior in terms of population, invests in seeking new forms of creativity, aimed at socio-economic recovery, quality of life, and a new place in the international market. This is an approach to urban development that redefines the 
role of human resources and invests in their education and mobility mainly through collaboration, information, and networking processes [17].

Irrespective, however, of the description that cities and settlements will receive, assessing the experience gathered to date, one sees that some of the major elements that enhance the attractiveness and radiance of a city or settlement include high accessibility combined with promotional activities in competitive sectors of production and technical and social infrastructure, infrastructure for new knowledge generation and for research, and mechanisms interconnecting knowledge infrastructure with local businesses (allowing for this knowledge to be integrated and converted into wealth and prosperity) and local businesses with international markets $[10,21]$. In other words, elements whose existence and evolution depend on securing top level human resources. It appears that human desires, motives, imagination and creativity can (in the form of urban resources) replace the significance of space, natural resources, and market accessibility. A new form of urban economy is created around the following axes: knowledge society and knowledge economy. Human resources (and not so much technology) are now the dominant developmental lever for cities and settlements. Attention is now shifting to citizens, who are called to contribute to addressing new realities through socio-economic, cultural, and political innovations. To find a solution to giving cities and settlements greater vitality and preventing demographic changes that would remove a population from its traditional environment and the history of its land, one should turn to the existence of creative citizens. These are citizens who are informed, educated, and aware; who understand the importance of preserving the authenticity and of feeding the imagination; and who also have the ability to combine knowledge for the purpose of either making it useful for specific applications or adding new value to it. These are conditions that are not guaranteed automatically, but only through actions for changing ways of thinking and pursuits $[3,16,17]$. To this end, education must play a crucial role as, led by knowledge, it enriches the interests of citizens; shapes ideology, culture, and social conscience; and contributing in a variety of ways to the establishment of a new creative class, which is not motivated solely from material benefits but also selects and seeks to live in more qualitative, creative, and exhilarating places [16-19]. It also appears that preserving the educational function in central areas of historic locales may also (under certain conditions) operate in a positive fashion [10,14]. This is because the urban space may constitute a "living workshop" for education structures, at the same time as they themselves, through their differing roles as educators, researchers, citizens, and neighbours, may function in their areas as powerful magnets, attracting functions, contributing, on the one hand to strengthening creativity and competitiveness while simultaneously assuring their nature $[29,30]$. This is worth pursuing.

On this basis and in an effort to search for new developmental models and planning practices, the EU has also (for quite some time now) started to steer its interest. Recognizing that the knowledge economy tends to become the economy that identifies itself within cities, and considering the now established trend of cities to regain their creativity, the EU has taken initiatives aimed at addressing urban problems by making use of the cities' local identity and promoting investing in human capital and innovation in an effort to enhance citizens' skills and ability to perceive and make use of new competitive tools with an open mind for quests and experimentation. These are mostly research initiatives, focusing on fields like history, tradition, culture, arts and letters, and the natural environment. Their objective is to advance environmental protection, socio-economic development, territorial cohesion, and cultural dialogue and to improve the mobility of people, goods, and capital. They are initiatives that transcend the logic of fragmented spatial planning interventions to the urban fabric so as to include socio-economic programming and management actions attempted through 'collaboration networks' among EU member states or between them and countries outside the EU. It is interesting to note that there is a turn to spatial functional units presenting strong dynamics and posing significant challenges, like the Mediterranean (the first case of reference). Based on this rationale, another equally challenging spatial functional unit to be investigated at a national level and beyond could be the Aegean Sea and more specifically its fragmented insular regions (the second case of reference) [11-13] (Sections 5-7). 


\section{Historic Locales and Urban Regeneration-Cultural Heritage as a Developmental Driver}

This section seeks to re-open the discussion on urban regeneration of historic cities and settlements and investigate the contribution that cultural heritage could make as a developmental factor in restarting local communities. For better understanding, the section is divided into three subsections (Sections 4.1-4.3). More specifically, Section 4.1 refers to the complexity which characterizes historic locales, highlighting issues of co-existence of the old and contemporary in these complex groupings. Section 4.2 brings out the importance of planning in establishing living creative loci, and Section 4.3 presents new challenges regarding the developmental role of cultural heritage in vulnerable places.

\subsection{Complex Groupings and Fragile Urban Landscapes-Issues of Coexistence}

Historiclocales constitute agencies that transmit the messages of the historical progress of a country, a city, or a settlement, which is why, to a major degree, they express the identity of a people. These places gather together elements and groups of history and memory of successive historical periods, which provide testimony to the culture of the people who created them. Within these, therefore, through successive dimensions which are received at every instant but also over time, the relationship between people and their past can ensure conditions to reconcile with the past while safeguarding contemporary everyday life. However, this cannot always be achieved, mainly due to the pressures put on this category of space as a consequence of intense urbanization, unplanned tourism development, and increasing demand for amenities. Over-exploitation of urban land, arbitrary expansions, loss of the multi-functionality of their fabric in combination with the constant penetration and dominance of tourist, recreational and free time usage to the detriment of housing and the sectors of traditional cottage manufacturing threaten the nature of these fragile urban landscapes, impede their organic inclusion in everyday life, and undermine their significance in the perception of local societies and the international community.

The co-existence of the old and contemporary in these complex groupings creates conditions for a two-way dynamic with positive and negative impacts on their quality, authenticity, and resilience. On the one hand, history, cultural heritage, and the unique features in their fabric and their socio-economic structure require protection. On the other hand, the variety and complexity of the problems these locales have to deal with in combination with the pressures they are under due to the manifold, often contradictory proposals for making use of them, due to the simultaneous involvement of parties with varied composition and conflicting interests dictate their modernization. Through this ongoing battle for dominance between conservation and change (where cultural heritage requires protection, interpretation and highlighting, while contemporary dynamics seek successful organization/ profitable management) there emerge a host of issues to be dealt with in the process of planning and design of these particular locales, which depend on their accessibility, the organization of movement and modernization of the infrastructure within them, their density, the incompatibility of uses and the degeneration of their conditions for habitation, the relations between public and private space and the vitiation of their cultural wealth. Issues that are crucial, given that, due to the multiple, frequently variegated impact on the historical, cultural, aesthetic and socio - economic content of historic loci as well as the time they operate in, they affect historical memory influencing understanding and respect for the importance of places in the consciousness of the population $[10,13,29,30]$ (Figure 2).

\subsection{Living Creative HistoricCities - The Requirement for Spatial Management and Planning}

Without a doubt, historicloci constitute a particular category of space, which requires a special strategy for organization, management, and planning that is able to ensure the conservation and protection of their authenticity, permitting the promotio, and highlighting of the individual spatio-socio-economic and cultural features of each, as well as the ease with which they adapt to whatever the dominant conditions and events are in each instance. Given that historic locales(despite the problems they incur, which are made worse by phenomenal of saturation, alteration, abandonment, 
exclusion, profiteering) remain significant guardians of cultural heritage and human resources, the discussion concerning their sustainable development gains particular interest, especially during periods of recession (like the one currently taking place) when decisions are reached with the sole criterion of economic growth, under conditions of great urgency, with a constant weakening of social participation, expanding deficits in issues of the productive base and practices of development discourse, ignoring the acquis of social and academic claims $[4,5,24]$. Under such circumstances, re-examining planning choices and priorities for interventions is required, making a goal of establishing "living creative places."

As far back as the 1950s, Laved an proposed we re-examine the precept that we preserve untouched whatever the present has received from the past because this frequently bothers the past and reduces the interest that the past should excite [31]. Cities evolve a condition which should not be impeded. In this spirit of evolution, the goal must be to comprehend the significance of historic loci in spatial development. This is obviously a matter of education and awareness-raising of the population. Only by raising awareness and mobilizing local societies and the global community will historic locales be able to function simultaneously as sites of history and memory but also loci for action and assertion. By the 1990s, we saw a more conscious turn away from the logic of urban re-development under terms of physical planning toward a new way of approaching loci, with a long-term strategic, multi-factorial nature, in line with which emphasis is placed on simultaneously adapting the social structures, the economic base, and environmental and cultural heritage, in terms of sustainability, thus seeking protection, equality, and justice. This new approach encountered in global theory and practice in urban regeneration, with the experience to confirm that ensuring the identity and quality of historicloci and their organic inclusion in contemporary life requires special handling, the key for which lies in the management of cultural heritage (tangible and intangible) and human resources [3,11,16-18,20,25,32]. Unfortunately, despite the recognition and uniqueness of historic loci, the process of planning around them does not always assure the requisite convergence of spatial planning and city planning and the strategic management of cultural heritage and human resources. These facts can create problems in their dynamics. However, how can historic cities or settlements manage to remain living, rather than dead museum sites? (Figure 3).

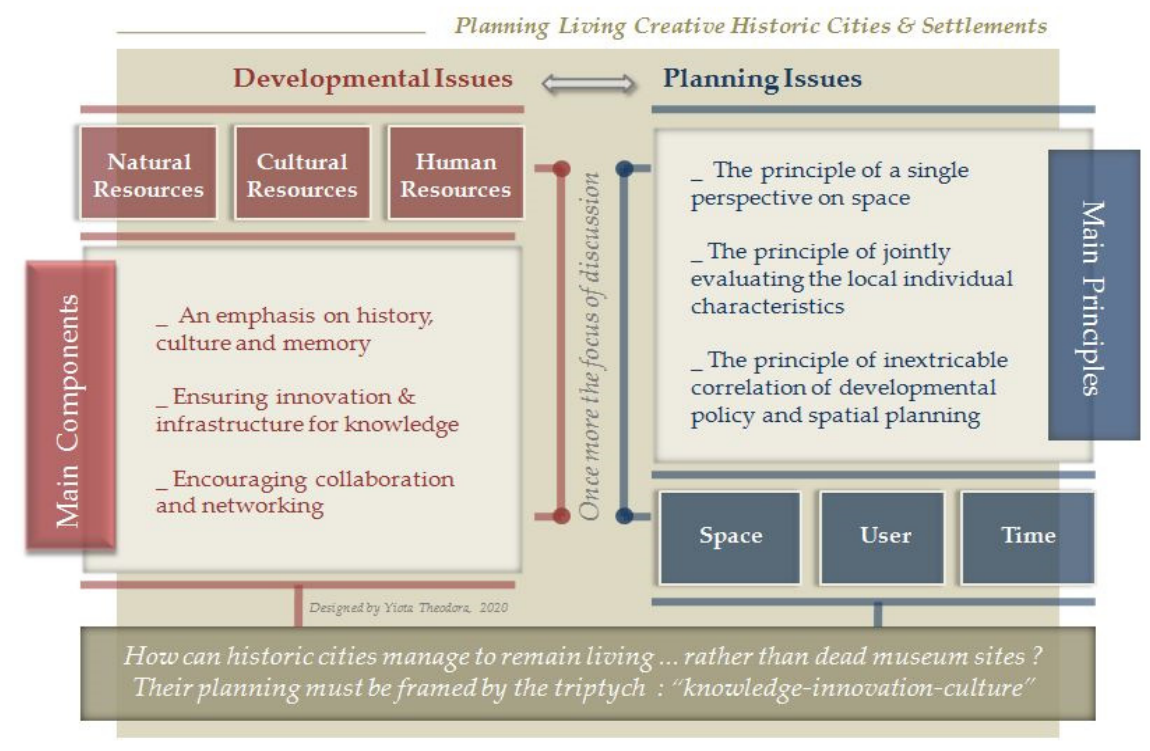

Figure 3. Planning Living Creative Historic Cities $\mathcal{E}$ Settlements (designed by Yiota Theodora, 2020).

Back in 1981, Lynch claimed that preserving authenticity and assuring quality along terms of evolution would render it possible to plan them while simultaneously also evaluating the following principles: vitality, capacity and fit of access, controlling the right of presence, use, action, familiarization, amendment, access, sense, efficiency, and justice [32]. These principles remain equally crucial and 
current today. At the same time, experience has shown that in the administration and planning of historic cities and settlements, we cannot neglect that (a) the past has a crucial capacity-it is unrepeatable and unique; (b) cultural heritage constitutes a component of pan-human civilization and therefore interest must supersede the narrow confines of local societies and expand to an ecumenical level; (c) historical memory plays a binary role-it is at the same time tangible proof of an era and the life of a society, but it is also a "teacher," as it constitutes a store of information that may respond to new needs, and therefore must be preserved and showcased in modern everyday life; and (d) the planning of historic loci must be undertaken while simultaneously evaluating the form, structure, uses, users, and timing in line with the following three principles: promoting ecological solidarity, dealing with social issues, and ensuring local democracy and transparency.

In this context, the claim could be made that an attempt to read, evaluate, and intervene in historic loci must be framed by the triptych of "knowledge, innovation, culture," with the following principles: (a) an emphasis on history, culture, and memory; (b) ensuring innovation and infrastructure for knowledge; and (c) encouraging collaboration and networking [10,29]. Its basic pillars are creative capital and the creative class, and the main developmental component will be cultural heritage [16-18]. This is because places are never simply a conglomeration of buildings and streets-they are the people who live and create within them. Thus, their beauty and quality are linked indissolubly with the education of people, the values they take with them, and the ideals for which they struggle without respite. Therefore, spatial planning should constitute the response of the soul to the needs and demands of population at any given time. Only in this way can places gain colour, light, life, countenance, and power. Only then can they create history. Only then can they become locales where we live with security and dignity, ready to dream of a better tomorrow $[29,30]$.

\subsection{Intangible Cultural Heritage as a Driver for Urban and Regional Development}

In line with conditions wherein how a creative environment is shaped relates ever more to the particular features of the areas, their history and cultural dynamics and interest in cultural heritage continues to grow-and is ever more strongly linked to creativity, particularly that dimension which exceeds the material (such as monuments or objects which have been preserved through the passage of time) to include the living expressions and traditions of countless groups and communities throughout the entire world, which have inherited them from their forebears and transmit them to their descendants (in most instances, from mouth to mouth). We are discussing the intangible cultural heritage, which, due to the wealth of its cultural objects, appears to be able to ensure to the agent of its expression a sense of identity and, subsequently, to the extent that he or she masters it and can recreate it $[10,13]$. We consider intangible cultural assets (no. 2 para. v, L. 3028/2002 on the Protection of Antiquities and Cultural Heritage in general, GG 153 A/28-6-2002. Greece ratified the UNESCOTreaty for the Protection of Intangible Cultural Heritage in 2006 (GG275/22-12-2006, Law no. 3521)) to be expressions, activities, knowledge, and information such as myths, customs, oral traditions, dances, actions, music, songs, skills, or techniques - traditional professions which constitute testimony of the traditional folk and scholarly culture. The sectors of intangible cultural heritage include the know-how connected to traditional handicrafts (weaving, pottery making, wood ship-building skills, etc.) which are the main object of the discussion in the research projects from the Mediterranean Sea (Sections 1.2, 5.1, 6.1 and 7.1).

As a motivational force for cultural diversity, intangible heritage is a fragile form of heritage, as it constitutes a living reality, which changes, evolves, and is transformed, enriched, and adapted following the social status quo of the community, which identifies itself through this, creates it, carries it, and transmits it from generation to generation. As a living social phenomenon, intangible heritage cannot be safeguarded and refreshed in a museum manner. Particularly, if we consider that the dominant concentration of its cultural objects is found in historic cities and in regional historic settlements-in sites, therefore, where, even though the structures of society, religion, and culture from the past are frequently developed under the conditions set by modern everyday reality, even when that is to the 
detriment of their carrying capacity and their form. These are sites where the coexistence of the old and the contemporary renders them, at the same time, sites of history and memory and as loci of action, staking a claim or even confrontation. The question is, how, and under what terms, must the management of intangible heritage be attempted in those sectors of space with a double, often contradictory nature, in order to function as an essential developmental component and a catalyst of urban regeneration? [10,13]

Even if there cannot exist a single commonly accepted approach, without a doubt, the museum approach to history and tradition is unable to provide a solution for re-starting local societies, increasingly highlighting the need for a more innovative approach, which will ensure the continuity and evolution of human culture. Beyond considering the value of isolated monuments and conserving their architectural value, the need to incorporate them into the city's fabric is increasingly recognized, highlighting issues of how they can be incorporated into the lives of residents and visitors. Accessibility, networking, and compatibility of use in combination with providing information on and highlighting cultural assets are promoted as crucial issues in dealing with the framework of the management of cultural wealth. Both United Nations Educational Scientific and Cultural Organization (UNESCO) and International Council on Monuments and Sites (ICOMOS) have carried out many years of research pertaining to the functions and values of cultural expression and its practices, which have opened the way for new approaches to understand and respect humanity's cultural heritage, while over the past few years, one of the main priorities of global collaboration has become to protect the cultural assets of our intangible heritage (See United Nations Educational Scientific Cultural Organization (UNESCO). Available online: https://en.unesco.org; International Council on Monument and Sites (ICOMOS) Available online: https://wwww.icomos.org/en. (Both accessed on 26 February 2020)) [20,33].

Under these circumstances, it is considered that, in order for intangible heritage to function as a developmental element, its management must be based on its multi-dimensional study, within the framework of which the variety of its interactions and interdependencies with the urban space and the everyday life of citizens will also be considered, ensuring a concomitant inclusion of the measures necessary to preserve cultural assets in planning principles. It is important amongst these to underline the significance of defining, documenting, researching, conserving, and promoting cultural assets; supporting the procedures and conditions for transmitting these through formal education and other means; and supporting actions to communicate, inform, and raise awareness of these in the broadest possible segment of society in order to regenerate expressions and elements of intangible heritage. These are issues which gain critical significance in the instance of historic cities and simultaneously underlining the importance of establishing a management strategy for cultural heritage and human resources and to place it within a broader urban policy $[3,10,13,17,20]$ (Section 8).

\section{Unlocking Creativity in Historic Cities and Settlements for Urban Regeneration}

In this section, the experience gained by the researches in the Mediterranean and the Aegeanis utilized in such a manner that their findings and proposals for local development could serve as a basis fordetermining the principles and guidelines that should govern the formulation of an overall urban developmental policy (Section 8). For better understanding, each proposal is presented in the same rationale, i.e., objectives and methodology (Sections 5.1 and 5.2).

\subsection{The Mediterranean Project: The Art-Related Professions and Know-How as Developmental Drivers}

The MEDNETA research project seeks to bring creativity back to historic city centres as a driver of the socio- economic, cultural, spatial development of cities, for enhancing their competitiveness in a globalized environment, and for improving the quality of urban space. It is a "Mediterranean cultural network to promote creativity in the Arts, Crafts \& Design (ACDs) as a means for the regeneration of communities inhabiting historic cities" [10-12,34-37]. Its scope is to enhance cross-border dialogue and cooperation among small and medium-size enterprises in the ACDs and all relevant actors. 
The project aims at (a) increasing the competitiveness of contemporary creative ACDs to turn these into a leading economic actor in historic cities; (b) promoting cooperation among professionals, bodies, local communities; (c) revitalizing local communities and network of economic activities forming the urban and social setting of historic city centres; and (d) utilizing stakeholders' experience to disseminate know-how. The main idea was that Mediterranean Partner Country (MPC) cities can contribute the instilled tradition of their products and techniques to inspire European cities, while European Union Mediterranean Country (EUMC) cities with their scientific-technological knowledge can share and transfer to MPC cities new practices to ensure unique products that are locally produced, promoted, and marketed. The project was implemented in historic cities from six Mediterranean countries, selected on the basis of their representativeness of the different types of challenges faced by inner city creative economies depending on their geographical context and stage of economic development. The cities were Athens, Greece (historic centre); Florence (Oltrano in historic centre) and Palermo, Italy; Valencia, Spain (Velluters); Medina of Tunis, Tunisia (Souk streets and alleys and in Oukala); Beirut, Lebanon (Mar Mikhael); and Hebron, Palestinian Authority (Old City and its surrounding area, Modern Hebron City). Each city participated in the proposed "cultural network" with key sectors-mainly sectors which could become promotional activities in their historic centres. More specifically, Athens with jewellery and garments; Florence and Palermo with textile, leather, jewellery, and plasters; Valencia with silk, leather jewellery, garments, ceramics, and furniture manufacturing; Medina of Tunis with jewellery, shoe making, garments, and wood coating with metal; Beirut with garments and furniture design; Hebron with pottery, ceramics, wood, shells, embroidery, and mosaic, glass [36,37] (Figure 4).

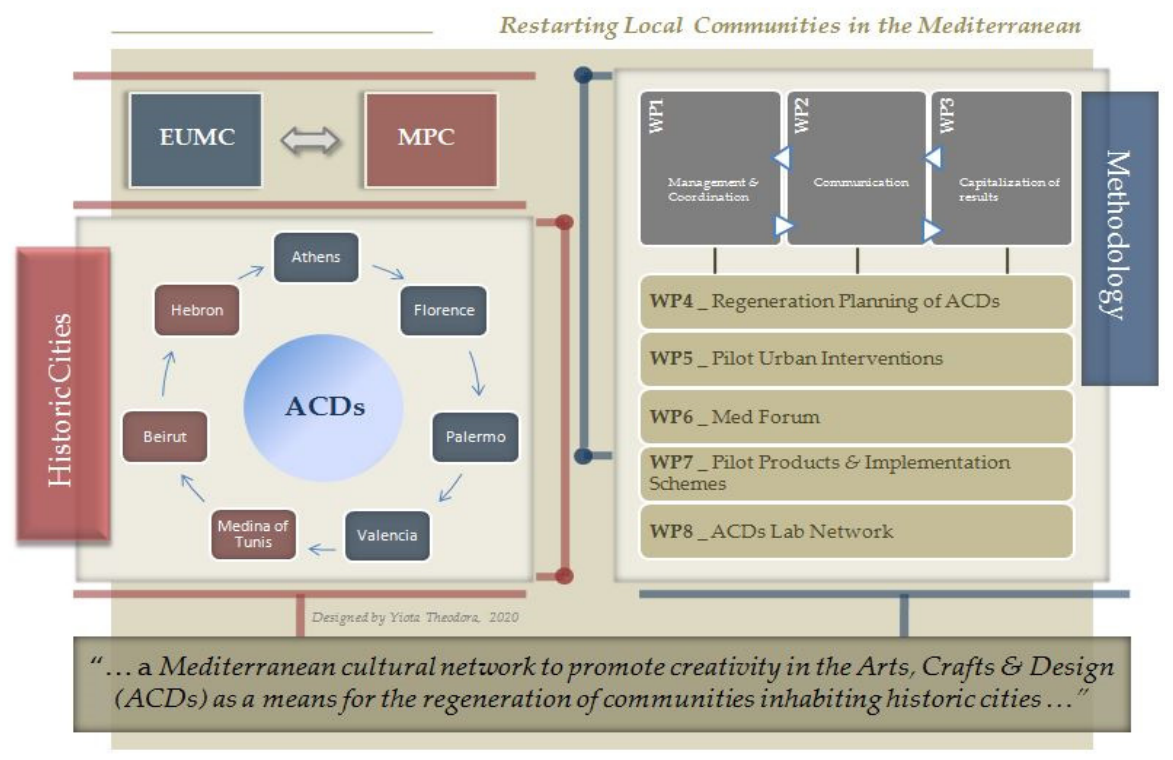

Figure 4. The Mediterranean Project: Participating Historic Cities and Methodology (designed by Yiota Theodora, 2020).

The specific project, having as its vision to establish a constant constructive communication and cooperation in the Mediterranean, set as main expected objectives (a) to create sustainable urban strategies and pilot projects for the revitalization of historic cities and regeneration of ACD professions, (b) to build new permanent forms of cross-border cultural and economic cooperation and networking in the ACDs among participating cities, (c) to produce innovation through development of synergies, exchange of best practices, transfer of know-how and infusion of new technology, (d) to deliver a "Mediterranean network" of ACD professionals as an open virtual workshop for multicultural dialogue, and an observatory to monitor the specific network after the project's completion. Thus, based on the methodology prepared by the partners (under the responsibility of the N.T.U.A.), the project (a) analysed and evaluated the existing data and conditions in each partner city on the following 
three basic interrelated levels: historical fabric (urban setting-character, cultural infrastructures, public space, accessibility, proximity),creative industry/ACDs' existence (tradition, know-how, culture, creative enterprises, entrepreneurship, and ACDs-their concentration within urban fabric and their economic vitality, education, new technologies, innovation, cooperation, networking, and product promotion), involved target groups (ACDs' owners, workers in creative industry, public or private stakeholders-directly or indirectly-involved, including Chambers, Associations, Ministries, Museums, Universities, Technical Schools, etc.; (b) conducted interviews to ACDs' representatives, while special interest was given to surveys in areas where ACDs were dominated; and (c) identified problems giving rise to critical issues to be addressed; and (d) defined the prospects and desirable basic networking levels between professionals and other relevant actors.

More specifically, in the context of promoting networking and for the purpose of achieving the intended interaction between the southand the north Mediterranean, the following activities were completed during the implementation period: (i) creation of a common register of professionals and relevant actors, as well as a geographical database for all cities, (ii) pilot products were specified and an exhibition, open to both professionals and the public, dedicated to the promotion of ACDs and the showcasing of their products as part of the cities' local identity and as a means of regeneration was organized, (iii) principles and guidelines that must govern all proposed urban interventions in the cities were set, and (iv) the "Med-Forum" topromotea dialogue maximising on the creativity, tradition and innovation between north and south Mediterranean cities, with participants from all the regions was created.

Parallel to the above, for opening and maintaining a democratic and productive dialogue with those directly involved as well as the general public, various communication actions were successful held among professionals, and local communities were informed. The implemented actions were (1) six SWOT Seminars, one in each city (i.e., evaluation of strengths, weaknesses, opportunities, and threats of local ACDs); (2) three open workshops in the North Mediterranean partner countries (EUMC) and three workshops-training programs in South Mediterranean partner countries (MPC), having as a main objective to establish cooperation among ACDs and local communities; (3) joint integrated strategy for revitalization of ACDs and specific strategy components for each city; (4) six pilot urban interventions (Athens, Florence, Valencia, Medina of Tunis, Beirut, and Hebron); (5) "Med Forum" to promote networking; (6) pilot products and rotated exhibitions open to the public (the first MEDNETA Rotating Exhibition was held in Beirut in November 2015 under the name "Weaving the Sea-Craftsmen and Designers from Across the Mediterranean Collaborate", and the second in Athens in December 2016); (7) joint pilot funding schemes; (8) Mediterranean ACDs Lab Network; (9) Cooperation Agreements; (10) MEDNETA Observatory; (11) MEDNETA Web GIS Platform (a database was organized, and a series of thematic maps was created for every participating city); (12) MEDNETA Guide for the ACDs Lab Network Capitalization; and (13) two international conferences were organized (the first in Medina of Tunis, December 2014;the second in Athens, December 2015), and special scientific editions both in English and Arabic were issued [10-12,34-37].

\subsection{The Aegean Project-The Natural-Cultural Heritage and Local Human Resources as Developmental Levers}

The ongoing research in the Aegean seeks to contribute on the debate regarding the necessity of the existence of an urban policy by underlining the need to change the manner in which we consider the management of natural, cultural and human resources in Greece. An answer is sought regarding how best we can achieve such a goal on the basis of spatial/sectoral/social collaborative networks (supralocal/transnational) focusing on the model of the "endogenous development". However, the real challenge is how these networks can contrive to function as people loci and not as homogenised impersonal "receptors" of hyper-concentrated activities/infrastructure. It is supported that in order to achieve it, priority must be given to (a) satisfying the real needs of the local population (i.e., needs as they are perceived by the users and not the administration) and (b) ensuring democratic planning 
in order to avoid adopting top-down developmental models and/or planning practices and decision making irrespective of the identity of the locus and the demands and priorities of the population [13].

The problem in Greece is that insular regions area vulnerable environment where networking, participatory planning, and the use of new innovative technologies and management of the human resources and cultural heritage remain as intentions or are faced with implementation hindrances. This is particularly the case for small isolated/border islands, the development of which is impeded by their distance from dynamic areas of the insular and/or continental space as well as the inability of local governments and communities to adapt to the new facts and utilize new planning practices.

The research focuses its scientific interest on vulnerable insular segments of the Aegean-more specifically, on territories where the agricultural economy continues to be dominant, while there is also an increasing interest in the development of various forms of tourism and recreation. Focus is on places where one can often encounter noteworthy elements of nature and culture at sea, in the coastal zone and the interior, as well as a network of historic cities and settlements and city ports of local and supralocal interests (as a part of the broader urban network) which is organised on islands of different dynamics and even under conditions of strong dominance of intra-and inter-municipal and regional inequities and the simultaneous inability to configure collaborations structures, not only at an island level, or between each other, or even with the continental segments of the country to which they belong or neighbouring countries.

On this basis, the ongoing research aims at making a contribution to this certain pilot reference field of vulnerable frontier segments, where there are many small islands with history and tradition. The challenge from a planning point of view is to transform these vulnerable places from "satellites" of dynamic insular or continental regions to "hubs" of spatio-functional collaboration networks with respect for their uniqueness. Along these lines, the research's main objective is to investigate for new alternative forms of networking, which are respectful of local identity and aim at territorial and socio-economic cohesion at an interregional (i.e., among islands) and local (island level) scale. In this rationale, the research claims that the local development of such valuable locales can be achieved by managing their human resources and natural-cultural heritage in a logical organisation of "cultural networks". A goal, which in order to become action, requires the existence of an overall insular policy that is integrally correlated with the attempted spatial planning (territorial or maritime) and the appropriated urban developmental policy which is still missing in Greece [10,13].

In this rationale, the main spatial levels of the ongoing research are (i) the Aegean Sea, (ii) its border regions, and (iii) small remote islands. At this stage we are mainly drawing on conclusions from the first level (i) and expect the debate to be enriched by the subsequent spatial levels at a later phase, in terms of defining the tools and indices used to assess and measure the dynamics of vulnerable regions through the definition of their radius of influence on a (trans)-regional or supranational level (Figure 5). 


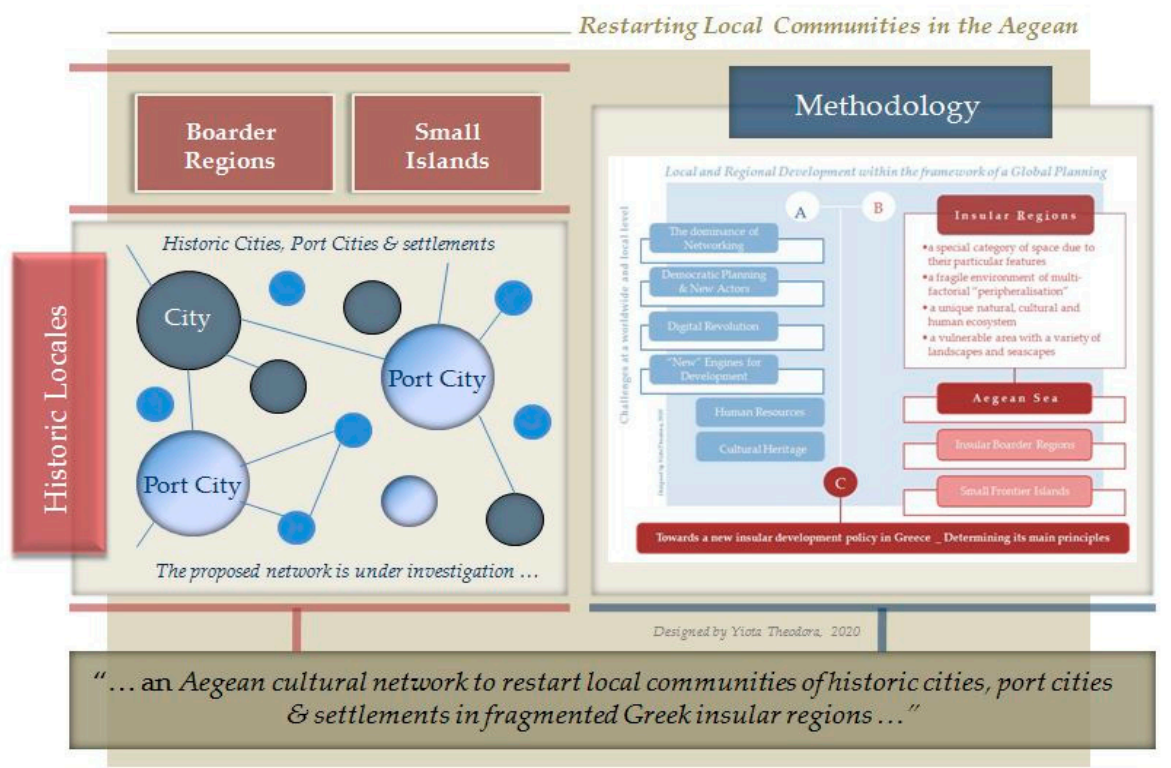

Figure 5. The Aegean Project: Restarting Local Communities in Historic Cities, Port Cities $\mathcal{E}$ Settlements in Fragmented Greek Insular Regions (designed by Yiota Theodora, 2020).

The proposed research methodology focuses on two parallel interrelated levels of research. The first research level (A) refers to new conditions/trends, involved in safeguarding local and regional development in the context of a global planning. The second level of research (B) focuses on insular space, seeking to highlight its particular features and to comprehend the problems that it faces (such as encirclement by the sea, proximity and accessibility, the blend of characteristics, depopulation, seasonality in social and economic life, the arid dry landscapes, and vulnerability to environmental challenges) (Figure 5). The complexity of this certain category of space requires a special approach to protection, management and development issues. Thus, at this stage of the investigation we are evaluating particular features and comparative advantages of the islands and the relationships of dependency and collaboration among them. The focus is on the isolated or frontier insular segments. More specifically, we are working on determining the main thematic areas of investigation in order to record, classify and evaluate islands' dynamics. Attention is paid to the structure of the urban network and the spatial distribution of transport and social infrastructure (i.e., education, culture, health, and welfare) in connection with the natural or manmade environment, and the administration and the local society (i.e., professional bodies, unions and associations, local organizations, and citizens' initiatives, etc). Similarly, the quality of natural and cultural heritage, and the uniqueness of the landscapes/seascapes are being evaluated. Last but not least, emphasis is placed on the recognition of existing local, trans-regional, and supralocal collaboration networks (i.e., spatial, sectoral, or socio-economic). We are working in this direction in order to understand the existing conditions and their developmental prospects. The goal is to identify those islands which will take on the role of hubsornodes in the proposed "cultural networks". At this stage, the selection of the appropriate indicators which will help us map the areas of interest in the Aegean and select the "key" islands is under investigation.

\section{Planning for Urban Sustainability in Historic Locales: Results from Field Surveys}

The section is divided into two main subsections in order to better present the results from the selected researches in the Mediterranean and Aegean Areas (Sections 6.1 and 6.2). 


\subsection{Findings from the Mediterranean Project}

Based on the results of field surveys, which took place in each participating city, regarding its urban environment (Section 6.1.1) and its traditional arts professionals (Section 6.1.2), as well as its different position in the transition process from "traditional handicrafts" to the "creative economy" (Section 6.1.3), the following are stated [10,12]:

\subsubsection{Urban Environment}

Besides each case's particularities, in the historic centres of participating cities, various historic, artistic, architectural, and construction values are met, which have influenced local societies in several ways. The research showed that their rehabilitation can contribute to urban revitalization and economic growth, if a methodology focusing on sustainability and protection is adopted.

In participating historic cities, despite the incidences of abandonment and damage to the urban environment, "creative sacks" continue to exist where traditional arts professions are concentrated with professionals who seek to remain there and who invest in their centres despite the problems involved and the decline in productive activity. A proposal is put forward to form spatial networks that promote entrepreneurship by including businesses in routes linking certain points of interest. Transport and communications systems must therefore undertake a catalytic role.

\subsubsection{Traditional Arts Professionals}

Professionals underlined the historical nature of their businesses (in most instances a family tradition) and how their businesses are irrevocably linked to the urban environment and elements of the city's cultural heritage. They reinforced how important it is that they operate in historic centres, presented the comparative advantages from their contiguity to these and their central location, including direct collaboration and networking with similar and complementary activities; increasing level of accessibility and connectivity; opportunities available in supply and disposal of products; and direct access to services or banks. They demanded improved urban infrastructures and declared themselves willing to contribute actively. They referred to the contraction of the traditional fields of endeavour and constantly declining export activity. They pinpointed weaknesses (namely, high operating costs, high rental rates, environmental pollution, safety deficiency, and technical infrastructures' quality) and supported the need to formulate networks for the collaboration of traditional enterprises and new creators in all stages of production up to and including product distribution. Professionals through their networking seek to promote their products and communicate with other similar enterprises at home and abroad. They need a "new" way to preserve traditional know-how and incorporate new technologies in the production process to improve and promote their products. They supported the importance of ensuring structures for education and training and communication, collaboration, and networking. In addition, they underlined the significance of organizing actions for constant contact to update and promote and highlight the products (following new trends). Finally, they are willing to form collaborations with the goal of producing pilot products.

\subsubsection{From "Traditional Handicrafts" to the "Creative Economy"}

Within the existing socio-economic conditions at the national and trans-national level, each partner city occupies a different position in the transition process from "traditional handicrafts" to "creative economy". Different positions do not necessarily mean that there are different issues at stake, but there are also common issues to be addressed, which vary in assessing their importance. At the same time, since the market dimensions have changed and competition is becoming global, there is a definite need for historic loci to increase the size of the primary market of ACDs. No matter where they are, ACDs have to deal with a new global reality which is interested not just in designing or manufacturing objects but mainly gives priority on how to structure the appropriate system of services to support creative production and ensure the appropriate urban environment in which they will operate. In this context, 
specifically concerning partner cities of the South Mediterranean, Hebron, and the Medina of Tunis have a long history in handicrafts production and form a "hub" for these crafts in Palestine and Tunisia. A common weakness is that most of the craftsmen use limited advanced technologies and techniques in producing and marketing their products. However, the preserved authenticity in their traditional products is what makes the know-how of ACDs unique. Regarding the partner historic cities of the North Mediterranean, their common characteristic is the incorporation of new technology in a great extent in order to improve the production process but also as the way to promote their products and as a common threat recorded the "losing of the know- how to do things". In addition, Athens and Valencia seems that have been affected strongly by the socio-economic crisis. The unsteady economic environment has serious and multiples effects on ACDs' operation. Beirut presents lots of similarities to partner cities of the North Mediterranean regarding ACDs' characteristics (i.e., the concentration of ACDs in the historic centre and their intention to stay in, incorporation of new technology to a great extent, a significant number of designers and supporting industries) in Mar Mikhael. However, the survey showed that changes during the last years in the neighborhood (e.g., changes in the morphology of the district result in an increase in rental prices, the deterioration of public space, its violation by recreational activities, etc.) have negative repercussions on the creative industries and might destroy the still emerging ACDs clusters.

Based on the above, taking into consideration the evaluation of ACD operation and dynamics, as well as the official positions of relevant actors, each participating city developed a strategy and defined the components for its historic centre socio-economic development, and a historic building within the core of each city was selected to operate as a landmark (Athens, Greece (Athens Traders Association in Athens Trade Triangle), Florence, Italy (an ISIA's building property adjacent to the Museum of Degli Innocenti); Valencia, Spain (Colegio Arte Mayor de la Seda, which is the Palace of the Master of the Guild of Velluters (Museum of Silk in Valencia)); Medina, Tunisia (Souk des Chechias: a network of stone paved roads, covered with arches and vaults with shops of traders and artisans, UNESCO World Heritage List, 1979); andHebron, Palestine (Msma'a, property of the Ministry of Religious Affairs, structured during 13th-15th century)) [35,37].

\subsection{Findings from the Aegean Project}

The evidence drawn on from the first stage (i) shows that the specific research can function as fruitful ground to re-exam "open" issues that have to be addressed in the context of an overall urban development policy, which is at an early stage at the European Union's level and is still missing in Greece (Figure 5). In this direction, the following are noted [13]:

(a) The Aegean Sea constitutes a unique natural, cultural, and human ecosystem, which is under strong and multiple pressures due to the coexistence of activities of a supra-local reach, which are often completely at logger heads with the carrying capacity of its places;

(b) Within Aegean insular regions, Greek islands, with a cultural heritage of multiple historical pasts, must manage the risk of their landscapes or seascapes being altered or their urban network going into decline or being abandoned. Among the main causes are their degree of accessibility and networking with dynamic areas of mainland or insular space, unregulated tourism development, and the planning of energy infrastructures which threaten their ecosystems;

(c) The insular regions of the Aegean Sea display spatial discontinuity or heterogeneity (mainly in terms of geopolitical pull, expanse, identity, dynamics) that often render it difficult (or impossible) to adopt proven policies, tools, or procedures. In such a fragmented environment, locales do not display the same resilience or adaptability, nor do they always have the required knowledge or appropriate infrastructure to successfully implement innovative practices for spatial management and planning. Thus, the study of local levels acquires particular interest, as well as the definition of the best territorial scale in order to evaluate as safely as possible their ability to use the available experience; 
(d) Islands and insular regions can play a vital role within a network-organised environment where "knowledge economy" prevails, only if we change the way we view their development, redefine the methodological approach framework, and set new evaluation criteria of the "insular phenomenon";

(e) Fragmented insular regions and small frontier islands can function as an interesting field of research. These are places transitioning from traditional to modern forms of development, which can still avoid the trends which would alter their local features. Their comparative advantage lies in their natural and cultural heritage;

(f) The sea continues to constitute a barrier, especially to isolate small and frontier islands and insular regions. Transportation/infrastructure planning and the digital technology can play crucial role to their connectivity and networking;

(g) We have to re-evaluate and re-define ways of dealing with spatial issues and take advantage of local competitive advantages, in other words of the territorial capital of a locale [38-41] (the "power of place" within a highly globalized environment).

\section{Restarting Local Communities through the Networking of Cultural Heritage and Tradition- New Challenges}

Both researches have delivered important lessons for a series of reasons, practical and beyond. More specifically, the followings are highlighted:

\subsection{Lessons Drawn from the Mediterranean}

On a practical basis, it is worth mentioning that (a) although many historic cities experience the pressure of deindustrialization, abandonment, qualitative degradation, deterioration of public space, historical buildings' alteration, or safety issues, inspiration, and creativity are still survived, expressed and reflected within their urban fabric. The research showed that enhancing creativity in synergy with culture and tourism can contribute to historic cities' revitalization, if we invest on cultural heritage preservation (tangible and intangible) and focus on human resources. (b) Despite the reduction in the number of enterprises, ACDs still hold a special place in the tradition and local economy in participating cities. The surveys evaluated their role as critical to urban regeneration and support that $\mathrm{ACDs}$ ' operation can reduce historic cities' continually transformation from productive centres to centres of services, recreation, and tourism and ensure their multifunctional character and vitality. (c) While the project was being implemented, with the goal of formulating strategies to regenerate creative activities in historic cities, it proceeded to record, analyse, and evaluate data and existing conditions in each city; located problems; highlighted crucial issues that had to be dealt with; defined prospects and desirable levels of networking for professional and relevant bodies, focusing on the following actions: (i) to inform and promote in order to establish relationships of collaboration and communication among interested parties on the one hand and the diffusion of information towards local communities on the other and (ii) to establish mechanisms to ensure the sustainability of the attempted networking that would endure beyond the completion of the research work.

In addition, new trends and challenges were brought out. Among them, it is noted that (a) there is a "new wave" of entrepreneurial survival through the development of socio-economic networks, which focuses on developing relations among new and traditional enterprises and young creators and on promotion towards the global market, with an emphasis on collaborative structures; (b) a turn away from the rationale of large projects and the renewal and redevelopment that emphasizes on physical planning to new alternative options that have a strong social dimension in developmental and environmental awareness and seeks to satisfy the real needs of the majority of citizens and create new job positions. The emphasis is to support small and medium-sized enterprises as they are more compatible with the environments in city centres and historical cores. The focus is on a new function for the city through workshops promoting art and tradition and initiatives for intelligent entrepreneurship 
through collaborative forms at a more global level. The emphasis is on political responsibility of the central and local government and public awareness that a democratic planning is needed [10-12,34-37].

\subsection{Lessons Drawn from the Aegean}

Unfortunately for Greece, a coastal and insular country with a naval history, despite the efforts made on the level of scientific research and political intensions, there has never to date been an integrated effort to deal with the insular space and its fragments' development. The absence of an overall island policy at the national level verifies that there are crucial issues (which remain open) that are needed to be resolved at the level of management and planning choices in order to eliminate instances of downgrading, deterioration, and abandonment, especially in vulnerable remote and insular border regions. Greek islands and insular regions can play a major role as developmental agents at global level if an overall insular policy is formulated based on the following principles: (i) protecting the natural and cultural heritage, (ii) planning infrastructures and activities in line with the carrying capacity of places as well as their resources, natural ecosystems and local identity, (iii) providing education to the population to raise awareness and cultivate a sense of joint responsibility and (iv) selecting the most relevant spatial level (i.e., is land orinsular unit) for planning and implementing interventions. The crucial issue for fragmented insular regions development is how to use best experience in its units and how local level can generate knowledge to feed the discussion on establishing a more cohesive island policy [13].

At the same time, new trends and challenges have been highlighted. Among them, the crucial challenge is how to identify strategies which are linked to "endogenous development"; mechanisms for spatial, sectoral, and social networking; procedures for democratic planning; and tools for incorporating new innovative technologies in the planning process and the everyday life. Safeguarding networks, establishing democratic planning, and using new technologies is not at all self-evident in areas where the local societies are unable to adapt to new conditions. This is where issues that have already been addressed and have yielded measurable results elsewhere remain unanswered. The main objective is to formulate an overall urban developmental policy and stop dealing with spatial problems in a fragmented manner.

Based on the above, in Greece the following still constitute "open" issues on the level of spatial management, development and planning: (i) the simultaneous use of space as administrative unit, natural element, and as a special spatial group which requires attention, either as a developmental factoror as a vulnerable area; (ii) the management of multiple expressions of a "new" urbanisation which is in progress; (iii) the making use of the dynamics of rural areas and their new relationship with central urban areas; (iv) the need for simultaneous study of mainland, insular, and maritime areas, which sets new issues at the level of administrative structure and research methodology of spatial analysis, management and monitoring; (v) the rise of "new" systems of social actors and governance structures under conditions of the digital revolution; and (vi) dealing with issues related to the attractiveness and "peripherality" of settlements, cities, and areas, which make it necessary to study the special spatial units (the principle of the jointly evaluating local particular features, see Section 1 and Figure 3) and the relationships between them.

Concluding, the contribution of bothresearches to the scientific dialogue could be significant as they: (a) highlight the importance of preserving and disseminating local traditions and know how as a means of modernization and restarting local economies and as a mechanism of urban recover; (b) mark out the power of dialogue and confirm that many difficulties could be overcome when we work on common goals within a spirit of friendship and cooperation; (c) confirm that we are moving toward new "developmental paths" which underlines not only the importance of establishing creative cross border cooperation among historic loci but also its preservation in time; and (d) recall the 'deficit', namely the lack of urban policy, part of which should be a management strategy of cultural heritage and human resources. For the above reasons, such research initiatives must be encouraged and promoted $[10,13]$. 


\section{Toward a New Overall Urban Policy-Open Issues and Challenging Perspectives}

The interest for urban development at policy-making level is a relatively recent one. It first appeared tentatively in the 1960s, at a time when urbanization was growing considerably, leading to the appearance of the first signs of the urban problem, and then became a political pursuit in the mid-1980s, when cities were recognized as major development cores. The problem is that there has been no separate urban developmental policy so far. Therefore, any measures taken to support cities are still integrated in other common policies or are put forward in the framework of research programs $[6,7,11]$. Another, equally important, problem is the orientation of urban interventions. Usually, they take the form of redevelopment (or urban renewal) programs, implemented in downgraded parts of cities, combined with the inclusion of traditional complexes in the urban fabric. Unfortunately, they are often corrective in nature and engage in upgrading urban space more from the viewpoint of physical planning. However, this fragmented approach - especially when socio-economic planning is either weakened or non-existent-generates problems in practice. This is due to the fact that spatial development or regulation issues, such as mitigation of intra-urban inequalities and strengthening cooperation among cities and settlements, are not addressed in a comprehensive manner [10,21].

There is no doubt that the framework of conditions and anticipated prospects-following the outbreak and spread of the multifaceted crisis-necessitates a different treatment of urban matters. It has become clear that if cities and settlements are to play a vital role within a network-based globalized environment where the knowledge economy prevails, we need to change the way we view urban development (Sections 1-3), redefine the methodological approach framework and set new evaluation criteria of the "urban phenomenon" $[9,13,21]$. Such actions are necessary in order to develop a new, more flexible, expressly formulated urban policy aimed at immediately including fragmented interventions in the framework of an overall urban approach. In this kind of approach, urban strategies (European, transnational, national, regional, local), given the multiplex problems they will have to address, will integrate economic growth, employment, and policies for the environment, transports and residence, investing in human resources without dismissing their spatial dimension (Sections 4-8).

In developing this new urban policy, the following critical issues that remain open, should be addressed: (a) the overall viewing of urban space and treatment of cities and settlements as part of an urban network [21]; (b) showing equal interest for dynamic cities and cities and settlements that can contribute in the creation of wealth and employment by utilizing knowledge generated elsewhere, in managing their comparative advantages [9]; (c) the protection, promotion, and management of the authenticity and specificities of each case, and addressing them on the basis of a supra-national dialogue $[10,13]$; (d) redefining the relationship between the city and countryside as a "unifying element" for spatial development in a manner that shall ensure the best possible use is made of sectors of intangible cultural heritage encountered in historic locales (i.e., historic cities and their broader areas; historic settlements in agricultural areas in continental or island areas) [29]; (e) dealing with issues concerning the currying capacity and resilience of historic locales under conditions of intensifying urbanization and tourism development, focusing on the management of cultural heritage, demographic growth, social cohesion and reformation of the local social network [13,30]; (f) human resources, mainly through focused actions for education, training and improving skills, creating positions of qualitative employment, and promoting innovation and the use of innovative new technologies [13,29]; (g) approaching urban interventions on the basis of equal joint evaluation of physical planning and socio-economic programming toward a strategic negotiating standpoint, along the lines of contemporary concepts on spatial development and the evaluation of existing conditions and prospects with local need and sustainable development of the space acting as drivers [29]; (h) the collaboration among different levels of governance (central, regional, local), focusing on new structures of participatory planning able to ensure the consent of citizens and those involved in the process of spatial development and planning [9,13]; and (i) the establishment of a monitoring group that would constantly observe and re-evaluate the pressures needs and demands in time and adaptation to new conditions [29]. 
Along these lines, there should be a crucial contribution from the academic and scientific world, especially in times of depreciating interest in the dimension of space within the framework of the planning process. Under these conditions, the academic community is called upon to provide innovative solutions on how to approach and teach topics of spatial development, so that universities can constitute an essential mechanism to assist planning at all the administrative levels $[10,13,29,30,33]$.

Funding: This research received no external funding.

Acknowledgments: The author warmly thanks the colleagues and students who have creatively contributed to the discussion with their knowledge and experience.

Conflicts of Interest: Author declares no conflict of interest.

\section{References}

1. Hall, P. Urban and Regional Planning, 4th ed.; Routledge: New York, NY, USA, 2002; pp. 147-187.

2. Roberts, P. The Evolution, definition and Purpose of Urban regeneration. In Urban Regeneration: A Handbook, 1st ed.; Roberts, P., Sykes, H., Eds.; British Urban Regeneration Association, Sage Publications Ltd.: London, UK, 2000; pp. 17-19. ISBN 978-0-7619-6717-0.

3. Parkinson, M.; Biankini, F. Cultural Policy and Urban Regeneration; University Press: Manchester, UK, 1994.

4. Schönwandt, W. Planning in Crisis? Theoretical Orientations for Architecture and Planning; Ashgate: Aldershot, UK, 2008.

5. Talvitie, A. Theory less Planning. Planning Theory. 2009. Available online: http://plt.sagepub.com/content/8/ 2/166 (accessed on 26 January 2020).

6. Atkinson, R. An Urban Policy for Europe; University of Portsmouth, School of Social \& Historical Studies North: Portsmouth, UK, 1999.

7. Parkinson, M. Urban Policy in Europe: Where Have We Been and Where Are We Going? Prepared under NODE Project on European Metropolitan Governance for Austrian Federal Ministry of Education, Science and Culture; European Institute for Urban Affairs/Liverpool John Moores University: Liverpool, UK, 2005.

8. Camhis, M. European Union and Cities: The urban dimension of Community policies. In Proceedings of the Conference Policy of Sustainable Urban Development in Greece, Jointly Organized by the Faculty of Architecture of the National Technical University of Athens and the Ministry of the Environment, Athens, Greece, 2 January 2005; Spatial Planning and Public Works: Athens, Greece, 2005; pp. 17-23.

9. Theodora, Y. Land Uses as An Expression of the Developmental Model in Space. In Issues of Methodological Consideration for Spatial Development and Regulation; A Collection of Papers; National Technical University of Athens_School of Architecture _ Department of Urban \& Planning: Athens, Greece, 2014. (In Greek)

10. Theodora, Y. Creativity and historic cities in the Mediterranean Sea. Attempting urban development by supporting tradition and the art professions. In Proceedings of the 54th Colloquium of the Association de Science Régionale de Langue Française (ASRDLF) \& 15th Conference of the Greek Section of the European Regional Science Association (ERSA-Gr), Cities \& Regions in a changing Europe: Challenges \& Prospects, Athens, Greece, 5-7 July 2017.

11. Enpi, C. A selection of ENPI CBC MED Projects, Mediterranean Stories. People cooperating across borders. In Cultural Heritage and Sustainable Tourism; ENPI-CBCMED Joint Managing Authority: Cagliari, Italy, 2014; pp. 24-27.

12. N.T.U.A.-School of Architecture (Beneficiary)/Greek-Italian Chamber-GIC; Social \& Economic Research Centre for the South of Italy _ CRESM; Superior Institute of Artistic Industries _ ISIA; Valencian Institute for Conservation and restoration of Heritage-IVC+r; Association for the Safeguarding of the Medina of Tunis_ASM; GAIA-heritage Institute of Urban Planning _ GAIAh; Birzeit University_Department of Architectural Engineering _ BZU. Mediterranean Cultural Network to Promote Creativity in the Arts, Crafts and Design for Communities' Regeneration in Historical Cities (MEDNETA); A Project funded by the European Union, ENPI-CBCMED Partnership; 2014-2015; GAIA-Heritage Institute of Planning: Lebanon, Beirut, 2015.

13. Theodora, Y. Aegean Sea-Challenges and Dilemmas in Management and Planning for Local Development in Fragmented Insular Regions. Heritage 2019, 2, 1762-1784. Available online: https://www.mdpi.com/25719408/2/3/108 (accessed on 1 February 2020). 
14. Theodora, Y. Approach to the effects of Greek regional universities on development of the country regions. In Regional Analysis and Policy. The Greek Experience; Coccossis, H., Psycharis, Y., Eds.; Springer: Heidelberg, Germany, 2008; pp. 249-270. ISBN 9783790820850. Available online: https: //ntua.academia.edu/YiotaTheodora (accessed on 1 February 2020).

15. Couch, C.; Fraser, C.; Percy, S. Urban Regeneration in Europe; Blackwell Science Ltd.: Oxford, UK, 2003.

16. Landry, C. The Creative City: A Toolkit for Urban Innovators (Paperback), 2nd ed.; Earthscan Publications: New York, NY, USA, 2008; ISBN 978-1844075980.

17. Landry, C. The Art of City Making; Earthscan Publications: London, UK, 2006.

18. Florida, R. The Rise of the Creative Class, 10th Anniversary Edition-Revised and Expanded; NY Basic Books: New York, NY, USA, 2014.

19. UNESCO. Creative Industries; UNESCO Culture Sector: Paris, France, 2009.

20. CIVVIH-ICOMOS. International Day of Monuments. Preservation development and monitoring of historic cities in 21st century. In Proceedings of the Conference and Annual Assembly of the International Scientific Committee of Historic Cities \& Villages, Corfu, Greece, 18-20 April 2002.

21. Theodora, Y.; Loukakis, P. Typology of Greek cities on spatial criteria of regional gravity, Aeihoros, Greece. 2007, v 7, pp. 128-157. Available online: https://ntua.academia.edu/YiotaTheodora (accessed on 30 January 2020).

22. Lambooy, G.J.; Moulaert, F. The economic organization of cities. An institutional approach. Inter-Natl. J. Urban Reg. Res. 1996, 20, 217-237. [CrossRef]

23. Nagy, G. Knowledge-Based Development: Opportunities for medium-Sized Cities in Hungary. Eur. Urban Reg. Stud. 2001, 8, 329-339. [CrossRef]

24. van Winden, W.; van den Berg, L. Cities in the Knowledge Economy: New Governance Challenges; Euricur: Rotterdam, The Netherlands, 2004.

25. Batten, D. Network cities: Creative urban configurations for the 21st century. Urban Stud. 1995, 32, 313-327. [CrossRef]

26. Castells, M. The Informational City; BasilBlackwell Publishers Ltd.: Oxford, UK, 1989.

27. Goldsmith, S.; Giuliani, R.; Daley, R.M. Entrepreneurial City; USA Manhattan Institute: New York, NY, USA, 1999.

28. Mahizhnan, A. Smart cities-The Singapore case. Cities 1999, 16, 13-18. [CrossRef]

29. Theodora, Y. The issue of teaching Spatial Planning _ Thoughts on dealing with modern requirements and challenges of development of space. In Maritime Space _ Urban Coastal Front_Port Cities, A Collection of Text on Spatial Planning; Theodora, Y., Ed.; National Technical University of Athens, School of Architecture, Urban Planning Research Lab: Athens, Greece, 2018; ISBN 978-618-80734-6-3. Available online: http: //www.arch.ntua.gr/publication/14430 (accessed on 8 January 2020). (In Greek)

30. Theodora, Y. Regional Unit of Piraeus_A Special Issue on Spatial Planning and Development; Theodora, Y., Ed.; National Technical University of Athens, School of Architecture, Department of Urban \& Regional Planning: Athens, Greece, 2019. Available online: https://ntua.academia.edu/YiotaTheodora (accessed on 8 January 2020).

31. Lavedan, P. Histoire de l'Urbanisme-Epoque Contemporaine; Henri Laurens Publications, 1st ed.; Henri Laurens Publications: Paris, France, 1952.

32. Lynch, K. A Theory of Good City Form; MIT press Cambridge: Massachusetts/London, UK, 1981.

33. Theodora, Y. GeoSites_Human Places, Educational \& Research Workshop: Young Planner Researchers Study Greece; Researcher's Night at the NTUA: Athens, Greece, 2017; Available online: http://www.arsakeio.gr/gr/ infrastructure/natural-historymuseum/educational-activities/33760-gewtopoi-topoi-anthrwpwn (accessed on 8 January 2020).

34. ENPI CBCMED, MEDNETA, Mediterranean cultural network to promote creativity in the arts, crafts and design for communities' regeneration in historical cities. In Proceedings of the MEDNETA 1st Conference, Tunis, Tunisia, 8-10 December 2014; pp. 30-45, ISBN 9789938142679.

35. ENPI CBCMED, MEDNETA, Mediterranean cultural network to promote creativity in the arts, crafts and design for communities' regeneration in historical cities. In Proceedings of the MEDNETA 2nd Conference Proceedings Cross border Cultural Dialogue to return Creativity in the Mediterranean Historical Centers: Strategies \& Tools, Athens, Greece, 14 December 2015; pp. 25-27, ISBN 978-618-80734-5-6. 
36. ENPI CBCMED Cross Border Cooperation in the Mediterranean, MEDNETA. In Proceedings of the Weaving the Sea _ Craftsmen and Designers from across the Mediterranean collaborate, A Catalogue with the Pilot Products, Beirut, Lebanon, 24 November-5 December 2015.

37. ENPI CBCMED Cross Border Cooperation in the Mediterranean, MEDNETA-Mediterranean cultural network to promote creativity in the arts, crafts \& design for communities' regeneration in historical cities. In A Guide to Promote the Role of ACDs In the Revitalisation of Historic Centres of Mediterranean Cities; GAIA-Heritage Institute of Planning: Beirut, Lebanon, 2015; pp. 8-15. ISBN 978-618-80734-4-9.

38. Camagni, R. Progress on an ex-ante assessment tool for territorial impact of EU policies: The TEQUILA model and beyond. In Proceedings of the ESPON Seminar, Evora, Portugal, 12-13 November 2007.

39. Kyvelou, S.; Sinou, M.; Baer, I.; Papadopoulos, T. Developing a South-European Eco-Quarter Design and Assessment Tool Based on the Concept of Territorial Capital, Sustainable Development. In Authoritative and Leading Edge Content for Environmental Management; Curkovic, S., Ed.; IntechOpen Publications: London, UK, March 2012; number 2374; ISBN 978-953-51-0682-1.

40. OECD. Territorial Outlook; OECD Publications: Paris, France, 2001; p. 300. ISBN 9789264189911.

41. Kyvelou, S. From Spatial Planning to Spatial Management: The Concepts of Strategic Spatial Planning and Territorial Cohesion in Europe; KRITIKI Publications: Athens, Greece, 2010; ISBN 978-960-218-671-8. (In Greek)

(C) 2020 by the author. Licensee MDPI, Basel, Switzerland. This article is an open access article distributed under the terms and conditions of the Creative Commons Attribution (CC BY) license (http://creativecommons.org/licenses/by/4.0/). 